\section{Nucleophilic Displacements in Supercritical Carbon Dioxide Using Silica-Supported Phase-Transfer Agents}

\author{
J oseph DeSimone, ${ }^{\dagger}$ Maurizio Selva, ${ }^{*, \neq, \S}$ and

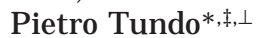

Department of Chemistry, University of North Carolina at Chapel Hill, Chapel Hill, North Carolina 27599-3290, and Dipartimento di Scienze Ambientali del 'Universita' Ca' Foscari, Calle Larga S. Marta, 2137-30123 Venezia, I taly

selva@univeit

Received September 8, 2000

\section{Introduction}

Carbon dioxide in both its liquid and supercritical states is receiving more and more interest for organic reactions as an attractive environmentally friendly solvent. ${ }^{1}$ Accordingly, several different reactions such as Diels-Alder cycloadditions, ${ }^{2}$ reductions and couplings of organic halides, ${ }^{3}$ cracking and rearrangements, ${ }^{4}$ hydrogenations, hydroformylation, and oxidation processes, ${ }^{1,5}$ and photochemical reactions ${ }^{6}$ are claimed to proceed in supercritical $\mathrm{CO}_{2}\left(\mathrm{scCO}_{2}\right)$.

However, the poor solubilizing power of the $\mathrm{scCO}_{2}$ for many polar compounds may represent a severe limitation, especially for reactions involving ionic moieties.

In the case of catalytic processes carried out with neutral or ionic complexes of transition metals, elegant solutions have been achieved following three different approaches: (i) the incorporation of " $\mathrm{CO}_{2}$-philic" fragments (e.g., perfluorinated groups) into the catalysts, either as ligands of the metal or in the counteranions, ${ }^{5 a, 7-9}$ (ii) the use of biphasic systems ( $\mathrm{scCO}_{2}$-ethylene glycol, $\mathrm{scCO}_{2}$-water), ${ }_{10}^{10}$ and (iii) the use of surfactant-stabilized water $/ \mathrm{CO}_{2}$ emulsions. ${ }^{11}$

When ionic or highly polar reagents are used, the introduction of polar cosolvents may over come the solu-

† University of North Carolina at Chapel Hill. E-mail: desimone@ unc.edu. Fax: +1919962 5467.

$\neq$ Universita' Ca' Foscari.

§ Fax: +39041 2578620.

$\perp$ E-mail: tundop@unive.it.

(1) Chemical Synthesis Using Supercritical Fluids; J essop, P. G., Leitner, W., Eds.; Wiley-VCH: 1999; pp 259-413.

(2) (a) Paulaitis, M. E.; Alexander, G. C. Pure Appl. Chem. 1987 59, 61. (b) Clifford, A. A.; Pople, K.; Gaskill, W. J .; Bartle, K. D.; Rayner, C. M. J. Chem. Soc., Faraday Trans. 1998, 94, 1451.

(3) Hadida, S.; Super, M. S.; Beckman, E. J .; Curran, D. P. J . Am. Chem. Soc. 1997, 119, 7046.

(4) (a) Karakas, G.; Dogu, T.; Somer, T. G. Ind. Eng. Chem. Res. 1997, 36, 4445. (b) M. E. Sigman, J. E. Leffler, J . Org. Chem. 1987, $52,3123$.

(5) (a) J essop, P. G.; I kariya, T.; Noyori, R. Chem. Rev. 1999, 99, 475. (b) Baker, A. Chem. Rev. 1999, 99, 453.

(6) (a) Tanko, J. M.; Blackert, J. F. Science 1994, 263, 203. Tanko, J . M.; Suleman, N. K.; Fletcher, B. J . Am. Chem. Soc. 1996, 118, 11958.

(7) Kainz, S.; Brinkmann, A.; Leitner, W.; Pfaltz, A. J . Am. Chem. Soc. 1999, 121, 6421.

(8) Burk, J .; Feng, S.; Gross, M. F.; Tumas, W. J . Am. Chem. Soc. 1995, 117, 8277.

(9) Palo, D. R.; Erkey, C. Ind. Eng. Chem. Res. 1999, 38, 2163.

(10) (a) Bhanage, B. M.; I kushima, Y.; Shirai, M.; Arai, M. Tetrahedron Lett. 1999, 40, 6427. (b) Bhanage, B. M.; I kushima, Y.; Shirai, M.; Arai, M. Chem. Commun. 1999, 1277.

(11) J acobson, G. B.; Lee, C. T.; J r; J ohnston, K. P.; Tumas, W. J . Am. Chem. Soc. 1999, 121, 11902. bility problem. In fact, under solid-liquid phase-transfer catalysis conditions (SL-PTC), nucleophilic displacements have been reported in $\mathrm{SCCO}_{2}$, providing that acetone is present as a cosolvent for the PT-catalyst. ${ }^{12} Y$ et, reactions proceed at moderate rates $\left(50{ }^{\circ} \mathrm{C}\right.$ : after $48 \mathrm{~h}, 15-60 \%$ conversions). Similarly, the Glaser coupling of alkynes has been claimed in $\mathrm{sCCO}_{2}$ in the presence of $\mathrm{MeOH}$ as a "polar modifier" which enhances the solubility of the reactive salts $\left(\mathrm{CuCl}_{2} \text { and } \mathrm{AcONa}\right)^{13}$

As a phase-transfer solvent, $\mathrm{sCCO}_{2}$ has been described in the extraction/methylation of chlorinated benzoates $\left(\mathrm{ArCO}_{2}{ }^{-}: \mathrm{Ar}=\mathrm{C}_{6} \mathrm{H}_{3} \mathrm{Cl}_{2}\right.$ and $\mathrm{C}_{6} \mathrm{H}_{2} \mathrm{Cl}_{3}$ ) from aqueous solutions: ${ }^{14}$ in this case, no cosolvents are required because of the high hydrophobic character of the nucleophiles.

Nucleophilic displacements have al so been reported in water $/ \mathrm{scCO}_{2}$ microemulsions (w/c-me) prepared with fluorinated surfactants (perfluoropolyether ammonium carboxylates: PFPE $\mathrm{CO}_{2} \mathrm{NH}_{4}$ ). ${ }^{15 a, b}$ More recently, el ectrogenerated radicals and cations have been stabilized in the water core of similar w/c-me (PF PE-phosphate). ${ }^{16}$

In $\mathrm{SCCO}_{2}$, efficient Diels-Alder reactions and enzymatic esterifications of polar substrates have been daimed with the use of amorphous silica gel, ${ }^{17,18}$ whose promoting role, although not well understood, is explained through the adsorption of the reactants which come into closer contact to each other, on the silica surface.

A related, but conceptually different approach can be conceived with supported onium salts as reagents: as reported by us, ${ }^{19,20}$ different anions $\left(\mathrm{I}^{-}, \mathrm{Br}^{-}, \mathrm{SCN}^{-}\right)$paired to bulky onium cations immobilized on alumina or silica gel, undergo fast nucleophilic substitutions in the presence of nonpolar media ( $\mathrm{n}$-heptane or toluene).

In this paper, we report for the first time that immobilized PT-agents provide also efficient anionic nucleophiles for reactions in $\mathrm{sCCO}_{2}$.

\section{Results and Discussion}

The $\mathrm{S}_{\mathrm{N}} 2$ displacement on n-octyl methanesulfonate (1) by bromide and iodide anions was chosen as a model reaction. All experiments were performed in $\mathrm{ScCO}_{2}$ as the solvent, at $50-70{ }^{\circ} \mathrm{C}$ and 130 bar (see Experimental Section). Silica-supported onium salts $(\mathbf{2} \mathbf{a}-\mathbf{e})$ were used either as reagents or as catalysts (Scheme 1 ). The results are reported in Table 1.

(12) (a) Dillow, A. K.; J immy Yun, S. L.; Suleiman, D.; Boatright, D. L.; Liotta, C. L.; Eckert, C. A. Ind. Eng. Chem. Res. 1996, 35, 1801. (b) Chandler, K.; Culp, C. W.; Lamb, D. R.; Liotta, C. L.; Eckert, C. A Ind. Eng. Chem. Res. 1998, 37, 3252.

(13) Li, J ,; J iang, H. Chem. Commun. 1999, 2369

(14) Croft, M. Y.; Murby, E. J .; Wells, R. J . Anal. Chem. 1994, 66, 4459.

(15) (a) Clarke, M. J .; Harrison, K. L.; J ohnston, K. P.; Howdle, S. M. J . Am. Chem. Soc. 1997, 119, 6399. (b) J acobson, G. B.; Lee, C. T., J r.; J ohnston, K. P. J . Org. Chem. 1999, 64, 1201.

(16) Ohde, H.; Hunt, F.; Kihara, S.; Wai, C. M. Anal. Chem. 2000, 72,4738 .

(17) Castillo, E.; Marty, A.; Combes, D.; Condoret, J . S. Biotechnol. Lett. 1994, 16, 169 .

(18) Weinstein, R. D.; Renslo, A. R.; Danheiser, R. L.; Tester, J . W. J . Phys. Chem. B 1999, 103, 2878.

(19) (a) Landini, D.; Maia, A.; Montanari, F.J . Am. Chem. Soc. 1978, 100, 2796. (b) Landini, D.; Maia, A.; Montanari, F.; Tundo, P. J . Am. Chem. Soc. 1979, 101, 2526.

(20) Tundo, P.; Badiali, M. Reactive Polym. 1989, 10, 55. 

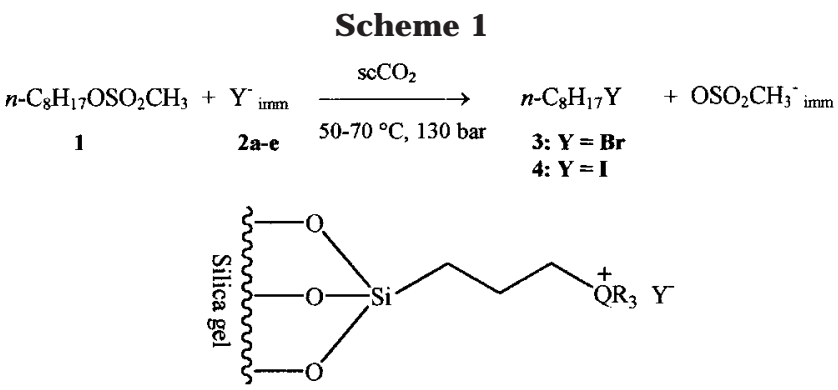

\begin{tabular}{|c|c|c|}
\hline $\begin{array}{c}\text { Supported } \\
\text { PT-agent }\end{array}$ & $\mathbf{R , Q}$ & $\begin{array}{c}\text { Loading: } \\
\text { mequiv } \mathbf{Y} / \mathrm{g}\end{array}$ \\
\hline & & \\
2a & $\mathrm{Me}, \mathrm{N}$ & $\mathrm{Br}: 0.56$ \\
$\mathbf{2 b}$ & $n$-Bu, N & $\mathrm{Br}: 0.19$ \\
& & I: 0.30 \\
2c & $\mathrm{H}$-Bu, N & I: 0.58 \\
2e & $n-\mathrm{Bu}, \mathrm{P}$ & $\mathrm{Br}: 0.26$ \\
\hline
\end{tabular}

(a) Bromide Displacements. Entries 1-7 show a comparative investigation of the bromide displacements on $\mathbf{1}$ carried out with $\mathrm{KBr}$, tetra-n-butylphosphonium bromide $\left(\mathrm{Bu}_{4} \mathrm{P}^{+} \mathrm{Br}^{-}\right)$, and silicas $\mathbf{2 a}$, b,e. Potassium bromide is totally ineffective for the reaction. In the presence of catalytic amounts of $\mathrm{Bu}_{4} \mathrm{P}^{+} \mathrm{Br}^{-}(0.1$ molar equiv with respect to 1 ), when $\mathrm{KBr}$ is used as it is or in aqueous solution, only a $10 \%$ conversion is reached even for prolonged reaction times (entries 2a,b). This suggests that if solid-liquid (SL; entry 2a) or liquid-liquid (LL; entry 2b) phase-transfer catalysis (PTC) occurs, an impractically low reaction rate results. Under such conditions, the formation of octyl bromide (3) is due rather to the reaction of $\mathbf{1}$ with $\mathrm{Bu}_{4} \mathrm{P}^{+} \mathrm{Br}^{-}$since the observed conversion ( 10\%) corresponds well to the quantity of the onium salt used. As proposed by Chandler et al.,12b because of the very low solubility of onium salts in $\mathrm{sCCO}_{2}$ the reaction may take place through the partition of $\mathbf{1}$ between the $\mathrm{CO}_{2}$ phase and the PT-agent itself. ${ }^{21}$ In fact, reactions carried out using the onium salt as the reagent show, after 180 min, conversions of 39 and $95 \%$ in the presence of 1.1 and 2 molar equiv of $\mathrm{Bu}_{4} \mathrm{P}^{+} \mathrm{Br}^{-}$, respectively (entries 3-4).

In contrast with the behavior of $\mathrm{Bu}_{4} \mathrm{P}^{+} \mathrm{Br}^{-}$, bromideexchanged silicas allow the bromide displacement on $\mathbf{1}$ to occur under LL-PTC conditions: in the presence of catalytic amounts of $\mathbf{2 e}(0.1$ and 0.05 molar equiv), conversions of 40 and $99 \%$ are achieved after $300 \mathrm{~min}$, at 50 and $70{ }^{\circ} \mathrm{C}$, respectively (entries $\left.7 a, b\right)$. n-Octyl bromide is isolated in $95 \%$ yield. The reaction takes place also with the use of silicas $\mathbf{2 a}, \mathbf{b}, \mathbf{e}$ as reagents: conversions up to $80 \%$ can be reached with a reactivity comparable to or somewhat lower than that of the onium salt $\mathrm{Bu}_{4} \mathrm{P}^{+} \mathrm{Br}^{-}$(entries 5, 6, and 7c).

(b) Iodide Displacements. Also iodide substitutions occurs with tetra-n-butylammonium iodide $\left(\mathrm{Bu}_{4} \mathrm{~N}^{+} \mathrm{I}^{-}\right)$as a reagent (entries 8-9). However, the PT-promoted iodide displacement appears to be slower than the correspond-

(21) Although we do not measure the solubility of $\mathrm{Bu}_{4} \mathrm{P}^{+} \mathrm{Br}^{-}$in scCO2, ref 12 a reports a solubility of $0.21 \mathrm{mmnol} / \mathrm{l}$ for tetra-nheptylammonium bromide (THAB) in $\mathrm{CO}_{2} / 5 \%$ acetone at $50{ }^{\circ} \mathrm{C}$ and 3000 psi. ing bromide process (entries 3-4 and 8-9). As already reported for nucleophilic displacements in anhydrous apolar solvents, ${ }^{19} \mathrm{Br}^{-}$is a better nucleophile than $\mathrm{I}^{-}$, since $\mathrm{Br}^{-}$is less polarizable in the absence of hydration.

Instead, iodide-immobilized silicas $\mathbf{2 c -} \mathbf{d}$ allow a significant enhancement of the reaction rate, yielding conversions that are more than three times higher than those achieved with $\mathrm{Bu}_{4} \mathrm{~N}^{+} \mathrm{I}^{-}$(entries 9-10 and 11-13). An even more striking result is manifest under LL-PTC conditions: while $\mathrm{Bu}_{4} \mathrm{~N}^{+} \mathrm{I}^{-}$is practically ineffective (entry 8), silica $2 e$ is a very active catalyst which allows a quantitative conversion after $3 \mathrm{~h}$ at $70{ }^{\circ} \mathrm{C}$ (entry 14; isolated yield $90 \%$ ). It should be noted that on functional ized silica iodide substitutions occur more readily than bromide ones (entries 5-7 and 11-14). The same behavior was also observed for halide displacements on $\mathbf{1}$ carried out in apolar solvents. ${ }^{20}$ Many factors may account for this situation: adsorption of the reagent, product, and nucleophile, as well as solvation-hydration of anions in the polar microenvironment provided by silicas, could come into play. Moreover, the fact that $\mathrm{CO}_{2}$ itself can adsorb on the silica surface ${ }^{22}$ introduces a further alteration in the partitioning of species between solid and fluid phases. ${ }^{18}$

The chemical bonding of onium salts to the inorganic support is of fundamental importance for the reaction to proceed. In fact, when a mechanical mixture of $\mathrm{Bu}_{4} \mathrm{~N}^{+} \mathrm{I}^{-}$ and silica gel is used, the iodide displacement is even slower than that performed with $\mathrm{Bu}_{4} \mathrm{~N}^{+} \mathrm{I}^{-}$alone (entries 8 and 13). This may be explicable through the following considerations: (i) immobilized onium salts distributed on the surface of the rigid solid support allow anionic nucleophiles to be highly available for the reaction; (ii) on the contrary, the nonlinked onium salt (entry 15) may adsorb on the non functionalized silica by forming agglomerated clusters into which nucl eophiles are hidden; (iii) the presence of free acidic geminal silanol groups over the silica surface (entry 15$)^{23}$ could give an inhibition of the nucleophile activity.

Under the investigated conditions, in the presence of stoichiometic amounts of functionalized silica, the use of $\mathrm{scCO}_{2}$ as a solvent does not improve reaction rates with respect to conventional organic solvents: for instance, at $60{ }^{\circ} \mathrm{C}$, iodide-exchanged silicas allow nucleophilic displacements on 1 to proceed quantitatively in $45-60 \mathrm{~min}$, in anhydrous toluene ${ }^{20}$ (compare to entry 12 of Table 1 ). However, it should be noted that the examined procedure has intrinsic benefits: $\mathrm{CO}_{2}$ has no environmental impact and, once the reaction is complete, it can be simply vented. Thus, products can be recovered by washing and filtering the functionalized silica which, eventually, can be regenerated through a simple protocol. ${ }^{20}$

\section{Conclusions}

The combined utilization of $\mathrm{CO}_{2}$ and PT-catalysis is a field of research in its infancy. The present study demonstrates that in $\mathrm{scCO}_{2}$ a new procedure for the nucleophilic displacements on n-octylmethanesulfonate by halide anions $\left(\mathrm{I}^{-}, \mathrm{Br}^{-}\right)$can be carried out with the use of silica-supported PT-agents $\mathbf{2}$. As reagents, compounds $\mathbf{2}$ can exhibit an activity even greater than that of

(22) Lemcoff, N. O.; Sing, K. S. W. J . Colloid Interface Sci. 1997, 61, 227.

(23) Sindorf, D. W.; Maciel, G. E. J . Am. Chem. Soc. 1983, 105, 1487. 
Table 1. Nucleophilic Displacements by $\mathrm{Br}^{-}$and $\mathrm{I}^{-}$on $\mathrm{n}-\mathrm{C}_{8} \mathrm{H}_{17} \mathrm{OSO}_{2} \mathrm{CH}_{3}$ in $\mathrm{scCO}_{2}$ as the Solvent

\begin{tabular}{|c|c|c|c|c|c|c|c|c|}
\hline \multirow[b]{2}{*}{ entry } & \multirow[b]{2}{*}{ PT-agent } & \multirow[b]{2}{*}{$\begin{array}{c}\mathrm{W}^{\mathrm{a}} \\
\text { (molar ratio) }\end{array}$} & \multirow[b]{2}{*}{$\begin{array}{l}\text { added salt }{ }^{\mathrm{b}} \\
\text { (molar ratio) }\end{array}$} & \multirow[b]{2}{*}{$\mathrm{T}\left({ }^{\circ} \mathrm{C}\right)$} & \multirow[b]{2}{*}{$\begin{array}{l}\text { time } \\
(\min )\end{array}$} & \multicolumn{3}{|c|}{ product $^{c}$} \\
\hline & & & & & & & $\begin{array}{c}\text { convn } \\
(\%)\end{array}$ & $\begin{array}{c}\text { isolated yield } \\
(\%)\end{array}$ \\
\hline 1 & none & & $\mathrm{KBr}(2)$ & 50 & 240 & 3 & trace, $<1$ & \\
\hline $2 a$ & $\mathrm{Bu}_{4} \mathrm{P}^{+} \mathrm{Br}^{-}$ & 0.1 & $\mathrm{KBr}(2)$ & & 360 & & 12 & \\
\hline $2 b$ & $\mathrm{Bu}_{4} \mathrm{P}^{+} \mathrm{Br}^{-}$ & & $\mathrm{aq} \mathrm{KBr}(2)^{\mathrm{d}}$ & & 180 & & 11 & \\
\hline 3 & $\mathrm{Bu}_{4} \mathrm{P}^{+} \mathrm{Br}^{-}$ & 1.1 & & & 180 & & 39 & \\
\hline 4 & $\mathrm{Bu}_{4} \mathrm{P}^{+} \mathrm{Br}^{-}$ & 2 & & & 180 & & 95 & \\
\hline 5 & $2 a$ & 1.1 & & & 180 & & 31 & \\
\hline 6 & $2 \mathbf{b}$ & 1.1 & & & 180 & & 41 & \\
\hline $7 a$ & $2 e$ & 0.1 & aq $\operatorname{KBr}(2.5)^{d}$ & 50 & 300 & & 40 & \\
\hline $7 \mathrm{~b}$ & $2 e$ & 0.05 & aq $\operatorname{KBr}(2.5)^{d}$ & 70 & & & 99 & 95 \\
\hline $7 c$ & $2 e$ & 2 & & 50 & & & 82 & \\
\hline 8 & $\mathrm{Bu}_{4} \mathrm{~N}^{+} \mathrm{I}^{-}$ & 0.1 & aq KI (1.1) d & & 180 & 4 & 7 & \\
\hline 9 & $\mathrm{Bu}_{4} \mathrm{~N}^{+} \mathrm{I}^{-}$ & 1.1 & & & 180 & & 19 & \\
\hline 10 & $\mathrm{Bu}_{4} \mathrm{~N}^{+} \mathrm{I}^{-}$ & 1.8 & & & 180 & & 22 & \\
\hline 11 & $2 c$ & 1.1 & & & 180 & & 60 & \\
\hline 12 & 2c & 1.8 & & & 180 & & 76 & \\
\hline 13 & 2d & 1.1 & & & 180 & & 60 & \\
\hline $14 a$ & $2 e$ & 0.05 & aq KI (2.5) ${ }^{\mathrm{d}}$ & 50 & 300 & & 60 & \\
\hline $14 \mathrm{~b}$ & $2 e$ & & aq KI $(2.5)^{d}$ & 70 & 180 & & 100 & 90 \\
\hline 15 & $\mathrm{Bu}_{4} \mathrm{~N}^{+} \mathrm{I}^{-} /$ & 1.1 & & & 180 & & 10 & \\
\hline
\end{tabular}

${ }^{a}$ All reactions were carried out at 130 bar. W: molar ratio between the nucleophile $\left(\mathrm{Br}^{-}\right.$or I$\left.^{-}\right)$and the substrate. ${ }^{b}$ Molar ratio between the added salt ( $\mathrm{KBr}$ or $\mathrm{KI}$ ) and the substrate. c Products were identified by GC/MS and by comparison to authentic samples. ${ }^{d}$ Aqueous solutions $(0.5 \mathrm{~mL})$ of $\mathrm{KBr}$ and $\mathrm{KI}$ were used. ${ }^{e} \mathrm{~A}$ mechanical mixture of $\mathrm{Bu}_{4} \mathrm{~N}^{+} I^{-}$(1.1 molar equiv with respect to 1 ) and silica gel was used for the reaction: 0.13 equiv of $\mathrm{I}^{-} / \mathrm{g}$ of silica.

conventional onium salts. However, the major advantage is evident under LL-PTC conditions: in the presence of immiscible $\mathrm{scCO}_{2}$ /aqueous phases, both $\mathrm{Bu}_{4} \mathrm{P}^{+} \mathrm{Br}^{-}$and $\mathrm{Bu}_{4} \mathrm{~N}^{+} \mathrm{I}^{-}$are inactive, while catalytic amounts of silicas $\mathbf{2}$ afford products (n-octyl halides) in quantitati ve yields. I norganic matrixes (i.e., silica gel) are particularly suitable supports because they have rigid structures that do not swell; swelling may occur with organic polymeric resins. ${ }^{24}$ Finally, as far as the anion nucleophilicity is concerned, the behavior of functionalized silicas in $\mathrm{scCO}_{2}$ seems to parallel a trend already reported for nonpolar solvents: ${ }^{20}$ iodide displacements appear faster than bromide ones, while the opposite is true in the case of onium salts.

\section{Experimental Section}

SAFETY WARNING: Operators of high-pressure equipments should take proper precautions to minimize the risks of personal injury. ${ }^{25}$

Silica-supported PT-agents $\mathbf{2 a}$-e were synthesized and anaIyzed as previously described: 26 the loading of the onium salts was $0.56,0.19,0.30,0.58$, and 0.26 mequiv per gram of silica, for $\mathbf{2 a}-\mathbf{e}$, respectively. n-Octyl methanesulfonate (1) was also prepared according to established procedures.27 Before each reaction, compounds $\mathbf{2 a}-\mathbf{e}$ were dehydrated by heating them under vacuum at $60^{\circ} \mathrm{C}$, overnight. All reactions were performed using a $25 \mathrm{~mL}$ stainless steel (hastelloy) cell equipped with sapphire windows which allowed the visual observation of the mixture.

Nucleophilic Displacements with Silicas $2 a-e$ and Onium Salts as Reagents. In a typical experiment, the reactor

(24) (a) Molinari, H.; Montanari, F.; Tundo, P.J . Chem. Soc., Chem. Commun. 1977, 639. (b) Molinari, H. Montanari, F.; Quici, S.; Tundo, P. J. Am. Chem. Soc. 1978, 101, 3920.

(25) J essop, P. G.; I kariya, T.; Noyori, R. J . Am. Chem. Soc. 1996, 118,345 .

(26) (a) Tundo, P.; Venturello, P.J . Am. Chem. Soc. 1979, 101, 6606. (b) Tundo, P.; Venturello, P. J . Am. Chem. Soc. 1981, 103, 856.

(27) Sekera, V. C.; Marvel, C. S. J. Am. Chem. Soc. 1933, 55, 345. was charged with the substrate (1, in the range of 30-100 mg) and the silica-supported reagent $\mathbf{2}$ (no more than $1 \mathrm{~g}$ in order to ensure the reaction mixture to be stirred) or the onium salt $\left(\mathrm{Bu}_{4} \mathrm{P}^{+} \mathrm{Br}^{-}\right.$or $\left.\mathrm{Bu}_{4} \mathrm{~N}^{+} \mathrm{I}^{-}\right)$, according to the amounts reported in Table 1 . The autodave was then pressurized with $\mathrm{CO}_{2}$ (SFC/ SFE grade) at approximately 60 bar by using an automatic syringe pump (ISCO model $260 \mathrm{D}$ ), and it was el ectrically heated at the desired temperature $\left(50^{\circ} \mathrm{C}\right)$, while the reaction mixture was magnetically stirred. The final pressure of 130 bar was reached by slowly adding the remaining $\mathrm{CO}_{2}$ to the reactor. Under these conditions, previous tests assured that compound 1 was completely soluble in $\mathrm{ScCO}_{2}{ }^{28}$ The reaction was allowed to proceed for the reported time (see Table 1); then, after cooling, $\mathrm{CO}_{2}$ was slowly vented by bubbling it into acetone $(5 \mathrm{~mL})$. The content of the cell was washed with additional acetone $(5 \mathrm{~mL})$, and the combined acetone solutions were analyzed by GC/MS (HP 5890, series II, fitted with a 30 m HP5MS column).

Nucleophilic Displacements with Silica 2e and Onium Salts as Catalysts. LL-PTC Conditions. According to the above-described procedure, a mixture of $\mathbf{1}(200 \mathrm{mg}, 0.96 \mathrm{mmol})$, the onium salt $\left(\mathrm{Bu}_{4} \mathrm{P}^{+} \mathrm{Br}^{-}\right.$or $\left.\mathrm{Bu}_{4} \mathrm{~N}^{+} \mathrm{I}^{-}\right)$or silica $2 \mathrm{e}(0.05-0.1$ molar equiv of $\mathrm{I}^{-}$or $\mathrm{Br}^{-}$with respect to $\mathbf{1}$ ), and an aqueous solution of $\mathrm{KX}\left(0.5 \mathrm{~mL} ; 2.1-4.8 \mathrm{M} ; \mathrm{X}=\mathrm{Br}^{-}, \mathrm{I}^{-}\right)$was made to react. In the case of silica $\mathbf{2 e}$, the acetone solutions recovered at the end of the reactions of entries $7 \mathrm{~b}$ and $14 \mathrm{~b}$ in Table 1 were dried over $\mathrm{Na}_{2} \mathrm{SO}_{4}$ and filtered. After rotary evaporation, n-octyl bromide and n-octyl iodide were isolated in 95 and $90 \%$ yields, respectively (>95\% pure by GC).

SL-PTC Conditions. The same procedure was applied with $\mathrm{Bu}_{4} \mathrm{P}^{+} \mathrm{Br}^{-}$in the presence of solid $\mathrm{KBr}$ (entry $2 \mathrm{a}$ of Table 1 ).

Acknowledgment. Interuniversity Consortium "The Chemistry for the Environment" (INCA) and National Science F oundation, Science and Technol ogy Center for Environmentally Responsible Solvents are gratefully acknowledged for financial support.

\section{J O001337M}

(28) In a $25 \mathrm{~mL}$ reactor, a complete miscibilty was warranted up to $500 \mathrm{mg}$ of $\mathbf{1}$. 